\title{
Choledochal cyst in childhood: review of 30 cases
}

\section{Cisto de colédoco na infância: revisão de 30 casos}

\author{
Danielle Nunes Forny'; Saulo Marcos Rebello Ferrante²; Vinícius Gomes da Silveira, TCBC-Rj²; Ivonete Siviero²; Vera Lucia Antunes

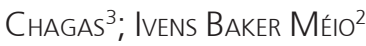

A $B$ S T R A C T

\begin{abstract}
Objective: To analyze and discuss the clinical data, diagnosis and treatment of a number of patients with cystic dilatation of the common bile duct of a Brazilian pediatric hospital. Methods: We analyzed 30 patients treated at the Martagão Gesteira Institute of Pediatrics and Child Care of the Federal University of Rio de Janeiro for 23 years , with statistical analysis of epidemiological data, clinical manifestations, diagnosis, treatment and postoperative outcome. Results: We observed a marked female predominance (73.4\% of cases), the diagnosis being made in the first decade of life in $90 \%$ of patients. The most prevalent clinical manifestation was jaundice ( $70 \%$ of cases) and the classic triad of choledochal cyst was not observed. Abdominal ultrasound was the first imaging examination performed, with a sensitivity of $56.6 \%$, with diagnostic definition in 17 children. Two patients (6.6\%) had prenatal diagnosis. All patients underwent surgical treatment, cyst resection with Roux-en-Y hepaticojejunostomy being performed in $80 \%$ of cases. The incidence of postoperative complications was $13.3 \%$ and the mortality rate was $6.6 \%$, ie two patients were diagnosed with Caroli's disease. Conclusion: The non-observance of the classic triad of choledochal cyst suggests that its incidence is lower than that reported in the medical literature. The surgical treatment of choledochal cysts, with resection and bilioenteric anastomosis, is safe even for small children.
\end{abstract}

Key words: Choledochal cyst. Jaundice. Bile Ducts. Anastomosis, Roux-en-Y. Cholangiocarcinoma. Child.

\section{INTRODUCTION}

$T^{1}$ he choledochal cysts consist of congenital abnormalities, with dilations of intra and / or extrahepatic bile ducts. Its occurrence is 1: 100,000 to $1: 150,000$ live births in the West and 1:1,000 in Asia1. They are more common in females in the ratio $3: 1$ to $4: 1^{1,2}$. While they may manifest in adulthood, about $60 \%$ of cases are diagnosed in the first decade of life $\mathrm{e}^{3}$. The most common diagnostic method is ultrasound. Currently, the recommended treatment is resection of the cyst or, when technically difficult, of the mucosa due to the high risk of late malignancy transformation ${ }^{1,4}$. Despite its low incidence, the choledochal cyst should be researched in children with suggestive symptoms, preventing the development of biliary cirrhosis or cancer of the biliary tract.

We present a series of 30 patients, discussing the epidemiological, anatomical classification, diagnostic and therapeutic methods, and correlating these data with the evolution and literature.

\section{METHODS}

We conducted a retrospective analysis of 30 patients with choledochal cyst attended at the Pediatric Surgery, Martagão Gesteira Institute of Pediatrics and Child
Care - IPPMG - of the Federal University of Rio de Janeiro - UFRJ - for a period of 23 years. From an initial group of 35 patients, five were excluded. Exclusion criteria were: divergence of data (one patient), transfer to another hospital for surgical treatment (one patient) and insufficient postoperative follow-up (less than three outpatient visits three patients). For inclusion in the study we considered patients of both genders, aged between one month and 13 incomplete years, surgery performed at the Department of Pediatric Surgery of IPPMG and attending at least three visits postoperatively. We analyzed the main clinical manifestations, age at which the diagnosis was made, exams, applied surgical procedures, complications, anatomical classification of cysts, histopathology of the liver and resected cysts, and postoperative outcome, with descriptive statistical analysis by calculating mean, median, standard deviation and percentage.

The project was approved by the Ethics in Research Committee of the Martagão Gesteira Institute of Pediatrics and Child Care, Federal University of Rio de Janeiro, under the number 291,124, CAAE 16047813.3.0000.5264.

\section{RESULTS}

Eight patients $(26.6 \%)$ were male and 22 (73.4\%) female. The average age of onset of symptoms

1. Martagão Gesteira Institute of Pediatrics and Child Care (IPPMG), Federal University of Rio de Janeiro - UFRJ; 2. Department of Surgery, Faculty of Medicine, UFRJ; 3. Department of Pathology, UFRJ. 
was 37.5 months $( \pm 28.2)$, with a median of 31.5 months, ranging from 4 to 100 .

The most common clinical manifestation was jaundice in $70 \%$ of cases ( 21 patients), followed by abdominal pain, present in $46.6 \%$ of patients (14 cases). Acute cholangitis was present in one child (3.3\%). Four children $(13.3 \%)$ were asymptomatic at the first surgical evaluation: two had prenatal diagnosis by obstetric ultrasonography, and two were evaluated due to hepatomegaly. One patient had a palpable abdominal mass (3.3\%) (Figure 1). The classic triad of choledochal cyst (abdominal pain, jaundice, and a palpable mass) was not observed.

Ultrasonography (USG) of the abdomen was done in 30 patients. Of these, only 17 were confirmed in this first evaluation, with a sensitivity of $56.6 \%$. In other tests, diagnoses were varied: choledocholithiasis (2), cyst of head of pancreas (1), pancreatic pseudocyst (1), hepatomegaly (1) and ascariasis of the biliary tract (1). In seven patients, we observed dilation or ectasia of the main bile duct, without being characterized as choledochal cyst. Two patients were diagnosed by prenatal ultrasonography in the third trimester of pregnancy. The ultrasound confirmation was made in the first and 23 months. In five patients computed tomography (CT) of the abdomen was indicated, demonstrating choledochal dilatation in three, with diagnosis in two, with a sensitivity of $40 \%$. Magnetic resonance imaging (MRI) was used in nine patients, being diagnostic in all cases, with a $100 \%$ sensitivity. It was indicated after abdominal ultrasonography in seven cases and after abdominal CT in two. In one patient the radiological diagnosis was made by percutaneous cholangiography and in another, by intravenous cholangiography.

The average age of diagnosis was 47.4 months $( \pm 36.7)$, ranging from one to 129 , with a median of 36.5 . Ninety percent of patients were less than ten years old.
The 30 patients underwent surgical treatment, at mean age of 50.2 months, and median $40.5( \pm 38)$, ranging from three to 130 months. The mean interval between diagnosis and surgery was 2.9 months.

The common bile duct cyst type I, according to the Alonso-Lej classification ${ }^{5}$ modified by Todani ${ }^{6}$, was observed in $93.4 \%$ of patients (28 patients), followed by cyst type V ( diffuse Caroli's disease) in 6.6\% (two patients).

In 24 patients (80\%) we performed resection of the choledochal cyst and Roux-en-Y hepaticojejunostomy. In five patients (16.6\%) we applied the Lilly technique, with resection of the choledochal mucosa and Roux-en-Y hepaticojejunostomy. In one patient with Caroli's disease we performed only a liver biopsy (Table 1). The removal of liver tissue for histological analysis was performed in 23 patients of the series $(76.6 \%)$.

Four patients $(13.3 \%)$ had immediate postoperative complications: one had choleperitoneum due to partial dehiscence of the biliodigestive anastomosis, which required reoperation, but progressed satisfactorily; three patients had acute cholangitis, two of them had Caroli's disease.

In eight patients (26.6\%) the liver had a cirrhotic aspect at laparotomy. None of the excised cysts had malignant degeneration or metaplasia at histopathology. Ninety percent of liver biopsies demonstrated microscopic structural abnormalities, hepatic fibrosis being the most common, present in $45.4 \%$ of samples, including the two patients who had had prenatal diagnosis. Cirrhosis was observed in $13.6 \%$. Two pathological examinations were normal (Table 2).

The mean duration of postoperative follow-up was 35.1 months ( \pm 30.4$)$, ranging from three to 104. In this period, two patients with Caroli's disease died, showing a mortality rate of $6.6 \%$. Twenty-eight patients showed

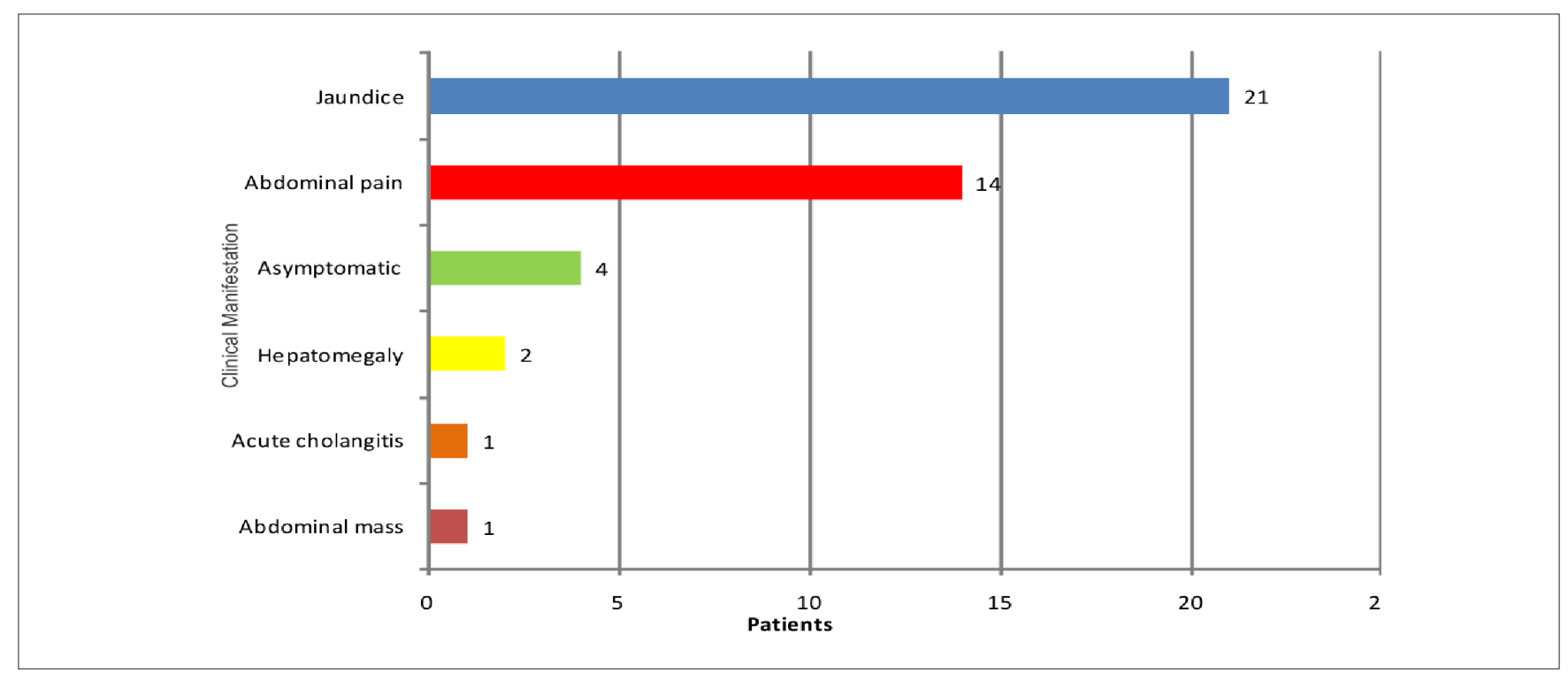

Figure 1 -

Clinical manifestations. 
clinical improvement, without jaundice nor signs of liver dysfunction, and appropriate development for the age.

\section{DISCUSSION}

Choledochal cysts are congenital malformations of bile ducts that represent a major diagnostic and therapeutic challenge for the pediatric surgeon, demanding a high degree of suspicion and efficient etiological investigation for the correct diagnosis and institution of appropriate treatment. Treatment should consist of resection of the dilated portion of the extrahepatic biliary reconstruction with a Roux-en-Y hepaticojejunostomy. When intrahepatic dilatation is very extensive, liver transplantation is an alternative.

The observation of the predominance of female patients in this sample, consisting of $73.4 \%$, is consistent with other studies on choledochal cysts ${ }^{1,5,6}$. The age at which the diagnosis was made, with the majority of patients in the first decade of life, agrees with other reports ${ }^{3,7}$, where $80 \%$ of cases are diagnosed before ten years of life, whereas only $25 \%$ of common bile duct cysts are seen in the first year ${ }^{2}$.

There is no consensus in the literature about the most common clinical presentation. Some authors $\mathrm{r}^{3,8}$ believe jaundice to be the main signal, similar to the result obtained in this sample. Other studies ${ }^{2,9}$, however, report that abdominal pain is the most prevalent symptom. Lilly argued that jaundice should be more commonly seen in infants and abdominal pain in older patients, probably due to the better capacity to verbalize ${ }^{10}$. Though abdominal pain, jaundice and abdominal mass are described as the classic triad of choledochal cyst ${ }^{5}$, their association was not observed in this study, in disagreement with data reported by other authors ${ }^{3,7,11}$. Although the concept that this presentation would be more frequent in children than in adults ${ }^{7}$, it is believed that early diagnosis in the current era would prevent the choledochal cyst from greatly increasing in volume, explaining the absence of an abdominal mass.

Currently, the preoperative diagnosis of choledochal cyst is mostly done by the USG, which has high sensitivity for the diagnosis of biliary tract disease ${ }^{12,13}$. It was the first complementary method used in the 30 patients, however, there was a sensitivity of only $56.6 \%$ in this sample, with a large number of tests being carried out by radiologists not specialized in pediatric diseases. This reinforces the idea that both clinicians, radiologists and surgeons require extensive knowledge of this malformation for the diagnosis to be established. Prenatal diagnosis of choledochal cyst is possible from the second trimester of pregnancy ${ }^{14}$, as noted in two children, and should always be confirmed after birth.

Although abdominal CT was performed in five patients, only in two the diagnosis was established. The low sensitivity is probably due to the low resolution of the images obtained in the first two patients, in the 80s, one with suspected choledocholithiasis and another with suspected cyst of head of pancreas. They were submitted to percutaneous cholangiography and venous cholangiography, respectively. These diagnostic modalities are no longer used, since they could be replaced by less invasive and more sensitive radiological methods ${ }^{1}$. On the other hand, in all nine patients who underwent MRI the diagnosis was correctly achieved, demonstrating that this method is a more sensitive diagnostic tool for the evaluation of diseases of the biliary tract than $\mathrm{CT}^{15}$. More recently, the three-dimensional reconstruction of MRI cholangiopancreatography allows better anatomical evaluation of biliary tract and pancreas. Another innovation is the virtual cholangioscopy, which allows preoperative radiological exploration of the bile ducts ${ }^{16}$.

Roux-en-Y hepaticojejunostomy was performed in 24 patients, and biliodigestive anastomosis associated with resection of the mucosal lining of the cyst, the Lilly technique, was performed in five patients. In this series, the low incidence of postoperative complications and good clinical outcome suggests that it is technically possible to safely perform biliodigestive anastomoses in children, as previously described ${ }^{17}$. One patient with Caroli's disease

Table 2 - Hepatic Histopathological changes.

\begin{tabular}{lrr}
\hline Histopathological changes & N & $\%$ \\
\hline Liver fibrosis & 10 & 45.4 \\
Ductular proliferation & 6 & 27.3 \\
Cholestasis & 5 & 22.7 \\
Perisinusoidal fibrosis & 3 & 13.6 \\
Fibrosis progressing to cirrhosis & 3 & 13.6 \\
Fibrosis progressing to cirrhosis & 2 & 9 \\
Hyperplasia of sinusoidal cells & 2 & 9 \\
Minimal changes & 2 & 9 \\
Normal & 2 & 9 \\
\hline
\end{tabular}

Table 1 - Surgical procedures.

\begin{tabular}{lrr}
\hline Surgical procedure & Patients (N) & $\%$ \\
\hline Roux-en-Y hepaticojejunostomy & 24 & 80 \\
Lilly's Surgery & 5 & 16.7 \\
Liver biopsy (isolated) & 1 & 3.3 \\
Total & 30 & 100 \\
\hline
\end{tabular}


was treated in the 80 s with palliative Roux-en-Y hepaticojejunostomy, since it would not be possible to perform liver transplantation in that period. In another patient with the same diagnosis due to advanced liver cirrhosis, it was decided only by liver biopsy, without biliodigestive derivation.

According to medical literature ${ }^{1,3,5}$, choledochal cysts type I correspond to up to $95 \%$ of all cases, confirming the demonstrated in this series, where the majority of cysts $(93.3 \%)$ represented a fusiform dilatation of the common bile duct.

The observed postoperative complications may be considered uncommon. The dehiscence of the biliodigestive anastomosis is infrequent $t^{1,18}$; we observed it in only one case, which was reoperated, with good evolution. The incidence of postoperative cholangitis was $10 \%$, agreeing with $8 \%{ }^{19}$ to $10 \%{ }^{20}$ reported in the literature. The highest incidence of cholangitis in this series can be explained because two of the three affected patients had Caroli's disease, which leads to biliary stasis, increasing the possibility of infection. The incidence of cholangitis in patients with Caroli's disease can reach $60 \%{ }^{21}$.

Although there are few reports on the microscopic abnormalities of the liver of patients with choledochal cyst, some studies claim that most patients, even those with prenatal diagnosis or operated in the first year of life, have changes in their liver biopsies as a result of biliary obstruction, with ductular proliferation, fibrosis and even cirrhosis $22-24$, agreeing with our results, since only two liver histopathology exams were normal. Not even the patients treated before one year of age showed normal liver histology. This reinforces the need for early diagnosis and treatment to prevent further damage to the liver parenchyma.

Postoperative monitoring demonstrated that the mortality rate was $6.6 \%$, two patients with type $V$ cysts, a higher incidence than that of Miyano et al. ${ }^{25}$, with zero mortality in a analysis of 180 cases in 30 years, and of Hung et al. ${ }^{17}$, also without mortality in a group of 25 patients followed for 20 years. Those authors do not report on their analyses the individuals affected by Caroli's disease, which usually evolve into irreversible liver failure, when resection of the affected segment or liver transplantation are not possible ${ }^{26}$. Transplanted patients have good postoperative outcome, preventing the development of cholangiocarcinoma ${ }^{27}$.

Given all these data, we conclude that jaundice in childhood must remain a warning sign for congenital malformations of the biliary tract. The lack of observation of the classic triad of choledochal cyst in the studied patients suggests that its incidence in childhood is lower than that reported in the medical literature. The surgical treatment of choledochal cysts, with resection and hepaticojejunostomy, is the treatment of choice and is safe even in young children. Diagnosis and treatment should be early to avoid a greater involvement of the hepatic parenchyma, whose severity depends on the degree of obstruction and time course.

\section{Acknowledgements}

To Rosangela Martins, Biostatistician of the Research Division of the Clementino Fraga Filho University Hospital - HUCFF, UFRJ, for the statistical analysis of this work.

\title{
RE S U M O
}

\begin{abstract}
Objetivo: analisar e discutir os dados clínicos, o diagnóstico e tratamento de uma série de pacientes portadores de dilatações císticas do colédoco de um hospital pediátrico brasileiro. Métodos: foram analisados 30 pacientes tratados no Instituto de Pediatria e Puericultura Martagão Gesteira da Universidade Federal do Rio de Janeiro durante 23 anos, com análise estatística de dados epidemiológicos, manifestações clínicas, diagnóstico, tratamento e evolução pós-operatória. Resultados: foi observada marcada predominância do sexo feminino (73,4\% dos casos), sendo o diagnóstico feito na primeira década de vida em $90 \%$ dos pacientes. A manifestação clínica mais prevalente foi a icterícia (70\% dos casos) e a tríade clássica do cisto de colédoco não foi observada. A ultrassonografia abdominal foi o primeiro exame de imagem realizado, demonstrando sensibilidade de 56,6\%, com definição diagnóstica em 17 crianças. Dois pacientes (6,6\%) tiveram diagnóstico pré-natal. Todos os pacientes foram submetidos a tratamento cirúrgico, sendo a ressecção do cisto com hepaticojejunostomia com Y de Roux realizada em $80 \%$ dos casos. A incidência de complicações pós-operatórias foi 13,3\% e a taxa de mortalidade foi 6,6\%, ou seja, dois pacientes com diagnóstico de doença de Caroli. Conclusão: a não observação da tríade clássica do cisto de colédoco nos pacientes avaliados sugere que a sua incidência seja menor que a relatada na literatura médica mundial. O tratamento cirúrgico dos cistos de colédoco, com sua ressecção e anastomose bíleodigestiva é seguro, mesmo em crianças pequenas.
\end{abstract}

Descritores: Cisto do Colédoco. Icterícia. Ducto Biliar. Anastomose em Y de Roux. Colangiocarcinoma. Criança.

\section{REFERENCES}

1. Congo K, Lopes MF, Oliveira PH, Matos H, Basso S, Reis A. Outcomes of choledochal cysts with or without intrahepatic involvement in children after extrahepatic cyst excision and Roux-en-Y hepaticojejunostomy. Ann Hepatol. 2012;11(4):536-43.
2. Yamaguchi M. Congenital choledochal cyst. Analysis of 1,433 patients in the Japanese literature. Am J Surg. 1980;140(5):6537.

3. Flanigan PD. Biliary cysts. Ann Surg. 1975;182(5):635-43.

4. Tyson GL, El-Serag HB. Risk factors for cholangiocarcinoma. Hepatology. 2011;54(1):173- 84. 
5. Alonso-Lej F, Rever WB Jr, Pessagno DJ. Congenital choledocha cyst, with a report of 2, and an analysis of 94, cases. Int Abstr Surg. 1959;108(1):1-30.

6. Todani T, Watanabe Y, Narusue M, Tabuchi K, Okajima K. Congenital bile duct cysts: Classification, operative procedures, and review of thirty-seven cases including cancer arising from choledochal cyst. Am J Surg. 1977;134(2):263-9.

7. Weyant MJ, Maluccio MA, Bertagnolli MM, Daly JM. Choledochal cysts in adults: a report of two cases and review of the literature. Am J Gastroenterol. 1988;93(12):2580-3.

8. Lee SS, Min PC, Kim GS, Hong PW. Choledochal cysts. A report of nine cases and review of the literature. Arch Surg. 1969;99(1):1928.

9. Chaudhary A, Dhar P, Sachdev A, Kumar N, Vij JC, Sarin SK, et al. Choledochal cysts-differences in children and adults. Br J Surg. 1996;83(2):186-8.

10. Lilly JR. Total excision of choledochal cyst. Surg Gynecol Obstet. 1978;146(2):254-6.

11. Kimura K, Ohto M, Ono T, Tsuchiya $Y$, Saisho H, Kawamura $K$, et al. Congenital cystic dilatation of the common bile duct: relationship to anomalous pancreaticobiliary ductal union. AJR Am J Roentgenol. 1977;128(4):571-7.

12. Haddad-Zebouni S, Hindy R, Rahi S, Slaba S, Aoun N, Abi Ghanem $S$, et al. Place de l'écographie dans l'ictère néonatal prolongé. À propos de 13 cas. Arch Pediatr. 1998;5(1):35-40.

13. de Vries JS, de Vries S, Aronson DC, Bosman DK, Rauws EA, Bosma $A$, et al. Choledochal cysts: age of presentation, symptons, and late complications related to Toddani's classification. J Pediatr Surg. 2002;37(11):1568-73.

14. She WH, Chung HY, Lan LC, Wong KK, Saing H, Tam PK. Management of choledochal cyst: 30 years of experience and results in a single center. J Pediatr Surg. 2009;44(12):2307-11.

15. Lam WW, Lam TP, Saing H, Chan FL, Chan KL. MR cholangiography and $C T$ cholangiography of pediatric patients with choledochal cysts. AJR Am J Roentgenol. 1999;173(2):401-5.

16. Saito $T$, Hishiki T, Terui $K$, Saito $Y$, Mitsunaga $T$, Terui $E$, et al. Use of perioperative, 3-dimensional magnetic resonance cholangiopancreatography in pediatric choledochal cysts. Surgery. 2011;149(4):569-75.

17. Hung $M H$, Lin LH, Chen DF, Huang CS. Choledochal cysts in infants and children: experiences over a 20-year period at a single institution. Eur J Pediatr. 2011;170(9):1179-85.
18. Chavhan GB, Babyn PS, Temple M, Langer JC. Diagnosis of postoperative bile leak and accurate localization of the site of the leak by gadobenate dimeglumine-enhanced MR cholangiography in a child. Pediatr Radiol. 2013;43(6):763-6.

19. Urushihara N, Fukumoto K, Fukuzawa H, Mitsunaga M, Watanabe $\mathrm{K}$, Aoba $\mathrm{T}$, et al. Long-term outcomes after excision of choledochal cysts in a single institution: operative procedures and late complications. J Pediatr Surg. 2012.47(12):2169-74.

20. Chijiwa K, Koga A. Surgical management and long-term followup of patients with choledochal cysts. Am J Surg. 1993;165(2):23842.

21. Pinto RB, Lima JP, da Silveira TR, Scholl JG, de Mello ED, Silva G. Caroli's disease: report of 10 cases in children and adolescents in southern Brazil. J Pediatr Surg. 1998;33(10):1531-5.

22. Nambijaran L, Taneja P, Singh MK, Mltra DK, Bhatnagar V. The liver in choledochal cyst. Trop Gastroenterol. 2000;21(3):135-9.

23. Lugo-Vicente HL. Prenatally diagnosed choledochal cysts: observation or early surgery? J Pediatr Surg. 1995;30(9):1288-90.

24. Suita S, Shono K, Kinugasa Y, Kubota M, Matsuo S. Influence of age on the presentation and outcome of choledochal cyst. J Pediatr Surg. 1999;34(12):1765-8.

25. Miyano T, Yamataka A, Kato Y, Segawa O, Lane G, Takamizawa $S$, et al. Hepaticoenterostomy after excision of choledochal cyst in children: a 30-year experience with 180 cases. J Pediatr Surg. 1996;31(10):1417-21.

26. Millwala F, Segev DL, Thuluvath PJ. Caroli's disease and outcome after liver transplantation. Liver Transpl. 2008;14(1):11-7.

27. Harring TR, Nguyen NT, Liu H, Goss JA, O'Mahony CA. Caroli disease patients have excellent survival after liver transplant. J Surg Res. 2012.177(3):365-72.

Received on 12/12/2013

Accepted for publication 05/02/2014

Conflict of interest: none.

Source of funding: none.

Mailing address:

Danielle Nunes Forny

E-mail: dforny@gmail.com 